\title{
Flavonoids from Cleistocalyx operculatus Buds and their Cytotoxic Activity
}

\author{
Byung Sun Min,* To Dao Cuong, Joo-Sang Lee, Mi Hee Woo, and Tran Manh Hung \\ College of Pharmacy, Catholic University of Daegu, Gyeongsan 712-702, Korea. *E-mail: bsmin@cu.ac.kr \\ Received May 28, 2010, Accepted June 23, 2010
}

Key Words: Cleistocalyx operculatus, Myrtaceae, Flavonoid glycoside, Cytotoxic activity

\begin{abstract}
Cleistocalyx operculatus (Roxb.) Merr and Perry (Myrtaceae) is a well-known medicinal plant, widely distributed and propagated in China, Vietnam and some other tropical countries. Several species of Cleistocalyx are used in folk medicine. In Vietnam, C. operculatus is commonly called "Voi". The flower buds ("Nu Voi") and leaves ("La Voi") have been used to make a beverage since ancient times. ${ }^{1}$ The buds are commonly used as an ingredient for tonic drinks in Southern China. ${ }^{2}$ The water extract of $C$. operculatus buds was shown to increase the contractility and decrease the frequency of contraction in an isolated rat heart perfusion system. ${ }^{3}$ It showed strong protective effects on lipid peroxidation in rat liver microsomes and on the $\mathrm{H}_{2} \mathrm{O}_{2}$ induced trauma of PC12 cells. ${ }^{4}$ C. operculatus extract showed inhibitory activity against the $\alpha$-glucosidase, rat-intestinal mal-
\end{abstract} tase, sucrase activities, and is considered a promising material for preventing and treating diabetes. ${ }^{5}$ Recently, the essential oil of the C. operculatus buds was investigated for its in vitro and in vivo anti-inflammatory activities. These results suggested that its essential oil might exert an anti-inflammatory effect by suppressing the expression of pro-inflammatory cytokines, which is mediated, at least in part, by blocking the NF- $\kappa \mathrm{B}$ activation. ${ }^{6}$ Previous phytochemical attention has led to the characterization of oleanane-type triterpenes, ${ }^{7,8}$ and flavonoids. ${ }^{2}$ Analysis of its leaf oil by gas chromatography (GC) and GCmass spectroscopy (GC/MS) has also been reported. ${ }^{9}$ Chalcone compounds from this plant possessed antioxidant and anticancer activities. ${ }^{10-12}$ In our previous study, $3^{\prime}$-formyl-4,4', 6'-trihydroxy2'-methoxy-5'-methylchalcone, 3'-formyl-4,6'-dihydroxy-2'methoxy-5'-methylchalcone 4'-O- $\beta$-D-glucopyranoside, $(2 S)$ 8-formyl-6-methylnaringenin, and (2S)-8-formyl-6-methylnaringenin $7-O-\beta$-D-glucopyranoside were isolated from EtOAcsoluble fraction and their radical scavenging activities were reported. ${ }^{13}$ In the present study, further phytochemical investigation of the water-soluble fraction of this plant led to the isolation of a new flavonoid glycosides (1), and six known compounds (2-7). Details of the isolation, structural determination and cytotoxic activity are described herein.

The MeOH extract of the buds of $C$. operculatus was partitioned into hexane-, EtOAc-, and water-soluble fractions. Chromatographic purification of the water-soluble fraction led to the isolation of seven compounds (1-7) (Fig. 1). Six of these were identified as gossypetin-8,3'-dimethylether-3- $O$ - $\beta$-Dgalactoside (2), myricetin-3'-methylether-3- $O$ - $\beta$-D-galactopyranoside (3), myricetin-3'-methylether (4), quercetin (5), kaempferol (6), and tamarixetin (7) by comparing their physical and spectroscopic data with previous reported papers. ${ }^{14-17}$
Compound 1 was isolated as a yellow amorphous powder and supported a positive ferric chloride reaction. The positive HR-FAB-MS analysis of $\mathbf{1}$ indicated an ion peak [M+ Na $]^{+}$at $\mathrm{m} / \mathrm{z} 547.1068$, which corresponded to the molecular formula $\mathrm{C}_{23} \mathrm{H}_{24} \mathrm{O}_{14}$. The IR absorptions at 3320 and $1660 \mathrm{~cm}^{-1}$ showed the presence of hydroxy and carbonyl groups, respectively, and the UV spectrum displayed two maximum bands at 262 and $381 \mathrm{~nm}$, characteristic of a flavon-3-ol. ${ }^{16,17}$ The ${ }^{1} \mathrm{H}$ NMR spectrum of 1 indicated the presence of two methoxy groups at $\delta$ $3.97(6 \mathrm{H}, \mathrm{s})$, proton signals were also observed at $\delta 6.90(1 \mathrm{H}, \mathrm{s}$, H-6) and 8.17 (2H, s, H-2', 6'). In addition, the ${ }^{1} \mathrm{H}$ NMR spectrum showed seven characteristic signals typical of a sugar moiety, including a peak at $\delta 6.41(1 \mathrm{H}, \mathrm{d}, J=7.6 \mathrm{~Hz})$ for an anomeric proton (H-1"). The ${ }^{13} \mathrm{C}$ NMR and DEPT spectra of 1 showed 23 signals, including nine oxygenated carbons, one carbonyl carbon at $\delta 179.6(\mathrm{C}=\mathrm{O})$, two methoxy carbons, and six carbon signals between $\delta 62.4$ and 104.6, which could be assigned to a sugar unit. The full NMR assignments and connectivities of $\mathbf{1}$ were determined by HMQC and HMBC spectroscopic data analysis. The HMBC spectrum confirmed the correlations between methoxy protons at $\delta 3.97(6 \mathrm{H}, \mathrm{s})$ and $\mathrm{C}-3^{\prime}(\delta 149.3)$, and at $\delta 3.97(6 \mathrm{H}, \mathrm{s})$ and $\mathrm{C}-5^{\prime}(\delta 149.2)$. Furthermore, correlations also observed in the NOESY spectrum of 1 (Fig. 2), indicated that the two methoxy groups in $\mathbf{1}$ were placed at the C-3' and

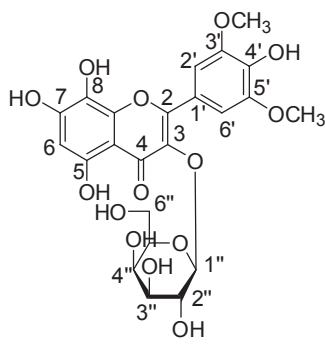

1

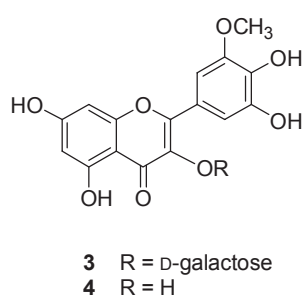

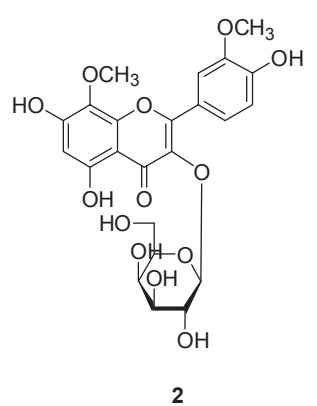

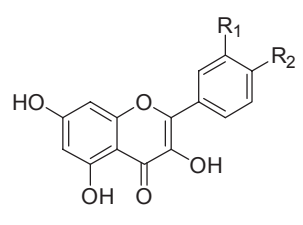

$5 \quad \mathrm{R}_{1}=\mathrm{OH}, \mathrm{R}_{2}=\mathrm{OH}$

$6 \quad \mathrm{R}_{1}=\mathrm{H}, \quad \mathrm{R}_{2}=\mathrm{OH}$

$7 \quad \mathrm{R}_{1}=\mathrm{OH}, \mathrm{R}_{2}=\mathrm{OCH}_{3}$
Figure 1. Chemical structures of isolated compounds 1-7. 


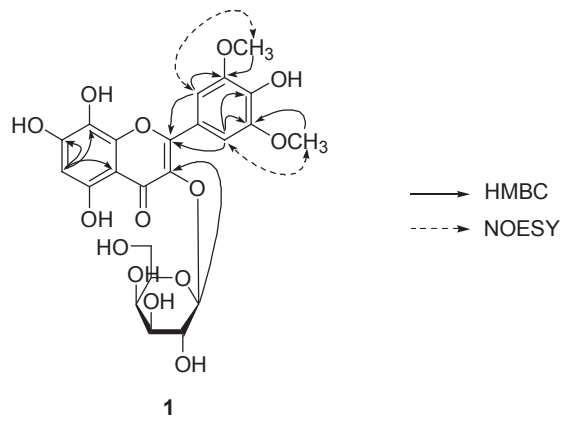

Figure 2. Selected HMBC and NOESY correlations of compound $\mathbf{1 .}$

Table 1. Cytotoxic activity of isolated compounds against cancer cell lines

\begin{tabular}{cccc}
\hline \multirow{2}{*}{ Compounds } & \multicolumn{3}{c}{$\mathrm{IC}_{50}(\mu \mathrm{M})$} \\
\cline { 2 - 4 } & Hela & HL-60 & A549 \\
\hline $\mathbf{1}$ & 38.7 & 16.5 & $>100$ \\
$\mathbf{2}$ & 42.1 & 18.1 & $>100$ \\
$\mathbf{3}$ & 45.5 & 15.7 & $>100$ \\
Adriamycin $^{a}$ & 0.70 & 0.18 & 5.72 \\
\hline
\end{tabular}

${ }^{a}$ Used as positive control.

C-5' positions. The correlation from the proton signal at $\delta 6.90$ $(1 \mathrm{H}, \mathrm{s})$ to the three quaternary carbons at $\delta 105.7(\mathrm{C}-4 \mathrm{a}), 127.5$ (C-8) and 155.7 (C-7) placed the location of this aromatic proton at C-6 (Fig. 2). The hydroxyl group was placed at C-8 as this carbon signal was shifted upfield (127.5 ppm) in its ${ }^{13} \mathrm{C}-\mathrm{NMR}$ spectrum. ${ }^{16}$ In addition, the two aromatic protons at positions C-2' and C-6' were further supported by the HMBC correlations between $\delta 8.17(2 \mathrm{H}, \mathrm{s})$ and $\delta 157.9(\mathrm{C}-2)$. To identify the sugar moiety, acid hydrolysis of $\mathbf{1}$ yielded D-galactose, as confirmed by co-TLC with an authentic sample and in combination with NMR data interpretation. The $J_{\mathrm{H}, \mathrm{H}}$ value $(7.6 \mathrm{~Hz})$ of the anomeric proton (H-1") indicated that galactose was linked via a $\beta$-linkage. ${ }^{16}$ In addition, the aromatic signal was shifted downfield at $\delta 135.5$ (C-3), which supported the location of galactose at this position. This finding was confirmed by the HMBC correlation between H-1" and C-3 (Fig. 2). Following the unambiguous NMR data assignment, the sugar moiety was further established by HMQC experiments. Thus, the structure of $\mathbf{1}$ was established as 5,7,8,4'-tetrahydroxy-3',5'-dimethoxyflavone-3- $O-\beta$-D-galactopyranoside.

Compounds 1-3 with a galactose moiety in the structures were evaluated for their in vitro cytotoxic activity against Hela, HL-60, and A549 cancer cell lines using MTT assay method with slight modification. ${ }^{18}$ As shown in the results presented in Table 1, compounds 1-3 showed weak cytotoxic activity against Hela cancer cell lines with $\mathrm{IC}_{50}$ values of $38.7,42.1$ and $45.5 \mu \mathrm{M}$, respectively. In the case of HL-60, these isolates displayed moderate cytotoxic activity with $\mathrm{IC}_{50}$ values ranging from of 13.7 to $18.1 \mu \mathrm{M}$. However, they showed very weak inhibitory activity against $\mathrm{A} 549$ cell lines with $\mathrm{IC}_{50}$ values over than 100 $\mu \mathrm{M}$. Plochmann et al. investigated the effects of methoxylation on cytotoxic activity by comparing the toxic affects of these compounds with unmethoxylated or less-methoxylated molecules. The higher methoxylated compounds were significantly more toxic than the less methoxylated molecules. ${ }^{19}$ Our results revealed that the cytotoxic activity of flavones decreased when 3'-hydroxyl was methylated (1-3), while the effect of 7-OH on the cytotoxic activity was uncertain. Furthermore, the existence of 3-Gal seemed to attenuate the cytotoxic activity of these compounds, suggesting that the sugar moiety could reduce the cytotoxic activity and that glycoside had a weaker cytotoxic activity than the corresponding aglycones, respectively.

\section{Experimental}

General experimental procedures. UV spectra were recorded on a JASCO V-530 spectrophotometer. IR spectra were obtained on a JASCO FT/IR 300-E spectrometer. NMR experiments were conducted on a Varian Unity INOVA 400 spectrometer. ${ }^{1} \mathrm{H}$ and ${ }^{13} \mathrm{C}$ NMR spectra were recorded at 400 and $100 \mathrm{MHz}$, respectively, and tetramethylsilane was used as the internal standard. FAB-MS and HR-FAB-MS analyses were performed on a Micromass QTQF2 mass spectrometer. TLC was carried out on Merck silica gel $\mathrm{F}_{254}$-precoated glass plates and RP-18 $\mathrm{F}_{254 \mathrm{~S}}$ plates. HPLC was performed on a Waters $600 \mathrm{E}$ multisolvent delivery system connected to a UV detector using RS Tech Optima Pak C18 column $(10 \times 250$ mm, $10 \mu \mathrm{m}$ particle size) semi-preparative columns.

Plant material. The buds of $C$. operculatus were purchased in Dong Xuan herbarium market, Hanoi, Vietnam, in July 2007 and identified by Professor Pham Thanh Ky, Department of Pharmacognosy, Hanoi University of Pharmacy. A voucher specimen (0160) was deposited in the herbarium of the Hanoi University of Pharmacy.

Extraction and isolation. The buds $(1.8 \mathrm{~kg})$ were extracted three times $(3 \mathrm{~h} \times 3 \mathrm{~L})$ with refluxing methanol. The $\mathrm{MeOH}$ extract was combined and concentrated to yield a residue which was suspended in water and then successively partitioned with $n$-hexane, EtOAc, and water residue. The water layer (18.0 g) was separated by Sephadex LH-20 silica gel column chromatography using a gradient of $\mathrm{MeOH}-\mathrm{H}_{2} \mathrm{O}$ (from 40:60 to 100:0), to yield seventeen subfractions (W1 $\sim \mathrm{W} 17$ ) according to their TLC profiles. Sub-fraction W5 (0.5 g) was purified by semipreparative HPLC systems [mobile phase (10 to $75 \% \mathrm{MeOH}$ in water for $60 \mathrm{~min}$ ), flow rate $5 \mathrm{~mL} / \mathrm{min}$; UV-detection at $254 \mathrm{~nm}$ ] resulted in the isolation of compounds $\mathbf{5}\left(12.5 \mathrm{mg} ; t_{\mathrm{R}}=38.5 \mathrm{~min}\right)$, $6\left(10.0 \mathrm{mg} ; t_{\mathrm{R}}=41.3 \mathrm{~min}\right)$, and $7\left(11.0 \mathrm{mg} ; t_{\mathrm{R}}=45.0 \mathrm{~min}\right)$. The sub-fraction W11 ( $0.25 \mathrm{~g})$ was further purified by semi preparative HPLC [mobile phase (10 to $75 \% \mathrm{MeOH}$ in water + $0.1 \%$ Trifluoroacetic acid for $60 \mathrm{~min}$ ), flow rate $5 \mathrm{~mL} / \mathrm{min}$; UV-detection at $254 \mathrm{~nm}$ ] resulted in the isolation of compound $2\left(2.8 \mathrm{mg} ; t_{\mathrm{R}}=37.4 \mathrm{~min}\right)$. The sub-fraction $\mathrm{W} 14(0.68 \mathrm{~g})$ was further purified by semi preparative HPLC [mobile phase (15 to $65 \% \mathrm{MeOH}$ in water $+0.1 \%$ Trifluoroacetic acid for 60 $\mathrm{min})$, flow rate $5 \mathrm{~mL} / \mathrm{min}$; UV-detection at $254 \mathrm{~nm}$ ] obtained compounds 1 (19.8 mg; $\left.t_{\mathrm{R}}=32.4 \mathrm{~min}\right), 3\left(6.0 \mathrm{mg} ; t_{\mathrm{R}}=40.1\right.$ $\mathrm{min})$, and $4\left(5.4 \mathrm{mg} ; t_{\mathrm{R}}=43.2 \mathrm{~min}\right)$.

$5,7,8,4^{\prime}$-Tetrahydroxy-3',5'-dimethoxyflavone-3- $O$ - $\beta$-Dgalactopyranoside (1): Yellow amorphous powder; UV $\lambda_{\max }$

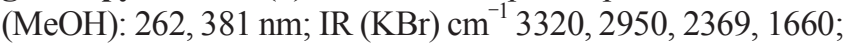


FAB-MS $m / z 547.1[\mathrm{M}+\mathrm{Na}]^{+}$; HR-FAB-MS $m / z 547.1068$ $[\mathrm{M}+\mathrm{Na}]^{+}$(calcd for $\left.\mathrm{C}_{23} \mathrm{H}_{24} \mathrm{O}_{14} \mathrm{Na}, 547.1064\right) .{ }^{1} \mathrm{H}$ NMR $(400$ $\left.\mathrm{MHz}, \mathrm{C}_{5} \mathrm{D}_{5} \mathrm{~N}\right) \delta 4.19-4.77(1 \mathrm{H}, \mathrm{t}, J=8.0 \mathrm{~Hz}, \mathrm{H}-2$ "; $1 \mathrm{H}, \mathrm{dd}, J=$ $2.8,8.0 \mathrm{~Hz}, \mathrm{H}-3$ "; 1H, d, $J=2.8 \mathrm{~Hz}, \mathrm{H}-4 "$; $1 \mathrm{H}, \mathrm{t}, J=6.0 \mathrm{~Hz}$, H-5"; 1H, dd, $J=6.0,10.8 \mathrm{~Hz}, \mathrm{H}-6 " \mathrm{a} ; 1 \mathrm{H}, \mathrm{dd}, J=6.4,10.8 \mathrm{~Hz}$, H-6"b), 3.97 (6H, s, $\left.\mathrm{OCH}_{3}\right), 6.41$ (1H, d, J=7.6 Hz, H-1"), 6.90 $(1 \mathrm{H}, \mathrm{d}, J=2.0 \mathrm{~Hz}, \mathrm{H}-6), 8.17$ (2H, s, H-2',6'). ${ }^{13} \mathrm{C}$ NMR $(100$ $\left.\mathrm{MHz}, \mathrm{C}_{5} \mathrm{D}_{5} \mathrm{~N}\right) \delta 57.3\left(3^{\prime}, 5^{\prime}-\mathrm{OCH}_{3}\right), 62.4\left(\mathrm{C}-6^{\prime \prime}\right), 70.3$ (C-4"), 73.9 (C-2"), 75.3 (C-3"), 78.1 (C-5"), 100.4 (C-6), 104.6 (C-1"), 105.7 (C-4a), 108.8 (C-2'), 108.8 (C-6'), 121.5 (C-1'), 127.5 (C-8), 135.5 (C-3), 141.2 (C-4'), 149.2 (C-5'), 149.3 (C-3'), 146.8 (C-8a), 155.2 (C-5), 155.7 (C-7), 157.9 (C-2), 179.6 (C-4).

Determination of sugar component. The monosaccharide subunit of $\mathbf{1}$ was obtained by acid hydrolysis. Compound $\mathbf{1}$ $(4 \mathrm{mg})$ in $10 \% \mathrm{HCl}$-dioxane $(1: 1,1 \mathrm{~mL})$ was heated at $80{ }^{\circ} \mathrm{C}$ for $4 \mathrm{~h}$ in a water bath. The reaction mixtures were neutralized with $\mathrm{Ag}_{2} \mathrm{CO}_{3}$, filtered, and then extracted with EtOAc. After concentration, each $\mathrm{H}_{2} \mathrm{O}$ layer (monosaccharide portion) was evaporated in vacuo to give residue, which was subjected to a silica gel column chromatography $\left(\mathrm{CHCl}_{3}-\mathrm{MeOH}-\mathrm{H}_{2} \mathrm{O}(55: 45\right.$ : $10)$ to yield D-galactose. The sugar was compared with authentic sample by TLC. The $R_{f}$ value for the above sugar was 0.19 .

Cytotoxic activity assay. The cancer cell lines were maintained in RPMI 1640, which included l-glutamine with 10\% FBS and $2 \%$ penicillin-streptomycin. Cells were cultured at $37{ }^{\circ} \mathrm{C}$ in a $5 \% \mathrm{CO}_{2}$ incubator. Cytotoxic activity was measured using a modified MTT assay. ${ }^{18}$ Viable cells were seeded in the growth medium $(100 \mu \mathrm{L})$ into 96 -well microtiter plates $\left(1 \times 10^{4}\right.$ cells per well) and incubated at $37{ }^{\circ} \mathrm{C}$ in a $5 \% \mathrm{CO}_{2}$ incubator. The test sample was dissolved in DMSO and adjusted to final sample concentrations ranging from 5.0 to $150 \mu \mathrm{M}$ by diluting with the growth medium. Each sample was prepared in triplicate. The final DMSO concentration was adjusted to $<0.1 \%$. After standing for $24 \mathrm{~h}, 10 \mu \mathrm{L}$ of the test sample was added to each well. The same volume of DMSO was added to the control wells. On removing medium after $48 \mathrm{~h}$ of the test sample treatment, MTT $(5 \mathrm{mg} / \mathrm{mL}, 10 \mu \mathrm{L})$ was also added to the each well. After $4 \mathrm{~h}$ incubation, the plates were removed, and the resulting formazan crystals were dissolved in DMSO $(150 \mu \mathrm{L})$. The OD was measured at $570 \mathrm{~nm}$. The $\mathrm{IC}_{50}$ value was defined as the concentration of sample that reduced absorbance by $50 \%$ relative to the vehicle-treated control.

Acknowledgments. This research was supported by research grants from Catholic University of Daegu in 2010.

\section{References and Notes}

1. Loi, D. T. Medical Publishing House, Hanoi 2001, 423.

2. Ye, C. L.; Lu, Y. H.; Wei, D. Z. Phytochemistry 2004, 65, 445.

3. Woo, A. Y.; Waye, M. M.; Kwan, H. S.; Chan, M. C.; Chau, C. F.; Cheng, C. H. Vasc. Pharmacol. 2002, 38, 163.

4. Lu, Y. H.; Du, C. B.; Wu, Z. B.; Ye, C. L.; Liu, J. W.; Wei, D. Z. Zhongguo Zhong Yao Za Zhi 2003, 28, 964.

5. Mai, T. T.; Chuyen, N. V. Biosci. Biotech. Biochem. 2007, 71, 69.

6. Dung, N. T.; Bajpai, V. K.; Yoon, J. I.; Kang, S. C. Food Chem. Toxicol. 2009, 47, 449.

7. Nomura, M.; Yamakawa, K.; Hirata, Y.; Niwa, M. Shoyakugaku Zasshi 1993, 47, 408.

8. Zhang, F. X.; Liu, M. F.; Lu, R. R. Zhiwu Xuebao 1990, $32,469$.

9. Dung, N. X.; Luu, H. V.; Khoi, T. T.; Leclercq, P. A. J. Essent. Oil Res. 1994, 6, 661

10. Ye, C. L.; Liu, J. W.; Wei, D. Z.; Lu, Y. H.; Qian, F. Cancer Chemoth. Pharm. 2005, 56, 70.

11. Ye, C. L.; Liu, Y.; Wei, D. Z. J. Pharm. Pharmacol. 2007, 59, 553.

12. Ye, C. L.; Qian, F.; Wei, D. Z.; Lu, Y. H.; Liu, J. W. Leuk. Res. 2005, 29, 887.

13. Min, B. S.; Thu, C. V.; Dat, N. T.; Dang, N. H.; Jang, H. S.; Hung, T. M. Chem. Pharm. Bull. 2008, 56, 1725.

14. Agnese, A. M.; Chiale, C. A.; Cabrera, J. L.; Juliani, H. R. J. Nat. Prod. 1986, 49, 528.

15. Harborne, J. B. Phytochemistry 1979, 18, 1323.

16. Thuong, P. T.; Kang, H. J.; Na, M.; Jin, W.; Youn, U. J.; Seong, Y. H.; Song, K. S.; Min, B. S.; Bae, K. Phytochemistry 2007, 68, 2432.

17. Braca, A.; Bilia, A. R.; Mendez, J.; Morelli, I. Fitoterapia 2001, 72,182

18. Kim Van, L. T.; Hung, T. M.; Thuong, P. T.; Ngoc, T. M.; Kim, J. C.; Jang, H. S.; Cai, X. F.; Oh, S. R.; Min, B. S.; Woo, M. H.; Choi, J. S.; Lee, H. K.; Bae, K. J. Nat. Prod. 2009, 72, 1419.

19. Plochmann, K.; Korte, G.; Koutsilieri.; Richling, E.; Iederer, P.; Rethwilm, A.; Schreier, P.; Acheller, C. Archives of Biochemistry and Biophysics 2007, 460, 1. 